\title{
BRANCH REPORTS
}

The autumn meeting of the Channel and S.E. branch was held at the Royal East Sussex Hospital, Hastings, on October 8, 1949.

The programme included the following papers and demonstrations:-

Papers: J. McMurray, "The Value of Biopsy Examinations"; P. Lazarus-Barlow, “Three Interesting Cases"; M. Haines, "The Male Toad Test for Pregnancy"; C. A. Holman, "Spontaneous Remission in a Case of Myeloid Leukaemia"; M. O. Skelton, "Two Malignant Ulcers in a Stomach"; M. Sadiq, M. O. Skelton, and H. G. Close, "A Case of Hepatoblastoma."

Demonstrations: A. G. Shera, "Secondary Bronchogenic Carcinoma Simulating Femoral Hernia" ; Myra K. Beatty, "Multicystic Ovaries with Characters of Arrhenoblastomata"; H. G. Close, "Myelo-lipoma of the Suprarenal"; P. Lazarus-Barlow, "Two-syringe Method for Exchange Transfusion" (see p.-) ; "? Primary Carcinoma of the Liver"; "Carcinoma of Bronchial Cyst"; "Primary Carcinoma of Fallopian Tube" ; "Ruptured Heart Muscle due to Passage of Electric Current "; J. McMurray, "? Endometriosis in Small Intestine causing Fibrosis and Obstruction"; "Krohn's Disease"; "Hydronephrosis due to Aberrant Vessels and Pelvic Stone"; "Aneurysm of Circle of Willis"; "Oesophagus and Stomach from a Case of "Izal' Poisoning" ; "Mid-brain Tuberculoma as Precipitating Focus of Meningitis"; "Intestinal Infarct" ; " ? Lymphosarcoma of Cervical Glands Diagnosed as Diphtheria "; "Healed Endocarditis showing Aneurysmal Sacs on Valve Cusps"; "Contusion of Ventricles of Heart"; "Cystic Lung in a Case of Cerebral Abscess"; "Aneurysm of the Aorta in a Male of Twenty-four" ; "Colon in a Case of Post-x-ray Colitis" ; C. J. HarwoodLittle, "Large Solitary Plasmacytoma"; F. Standish, "An Unusual Specimen."

A meeting of the West Mercian branch was held at Dudley Road Hospital, Birmingham, on October 15, 1949, when the following papers were read and specimens demonstrated.

Papers : S. Sevitt, “An Investigation into Two Hospital-infected Cases of Tetanus " ; P. Kidd, "The Chown Method of Rhesus Typing : a Warning."

Demonstrations : H. S. Barr, "Congenital Granular Cell Myoblastoma of the Gum " ; "A Unique Form of Intestinal Obliteration"; "Accessory Tracheal Bronchus without Accessory Lung"; B. T. Davis, "Eosinophil Leukaemia" ; G. H. Grant, "Myxoma of Bladder"; F. E. D. Griffiths, "Two Cases of Renal Abnormalities"; P. Kidd, "? Reticulosis of Stomach"; "Two Tumours from the Fingers for Diagnosis"; Ian Mackenzie, "Pulmonary Adenomatosis"; A. G. Marshall, "A Case of Bone Marrow Dysplasia for Diagnosis"; A. P. Prior, "Series of Chorio Allantoic Membranes" ; C. W. Taylor, "Pulmonary Embolism by Amniotic Fluid"; K. S. Thompson and G. Cruikshank, "Phase Contrast Microscopy for Urine and Body Fluids"; K. S. Thompson and G. Gilliatt, "Uterine Endometriosis"; W. Whitelaw and A. E. Chaplin, "Bronchial Adenoma"; "Tumours of the Thyroid." 